\title{
Chemical Pleurodesis Using Viscum album Extract in Gorham Disease Complicated with Chylothorax
}

\author{
Suk Ju Cho ${ }^{1}$ and Su Wan Kim ${ }^{2}$ \\ 'Department of Anesthesiology and Pain Medicine, ${ }^{2}$ Department of Thoracic and Cardiovascular Surgery, Jeju National University Hospital, \\ Jeju National University School of Medicine, Jeju, Korea
}

Gorham disease, also known as massive osteolysis, is characterized by unregulated proliferation of lymphatic or vascular capillaries within bone, resulting in destruction and replacement with angiomatous tissue. This disease can lead to chylothorax that can be lethal. Viscum album extract from European mistletoe is a complementary anti-cancer drug which is commonly prescribed in many European countries and is considered as a new generation of chemical agent for pleurodesis. A 14-year-old girl presented with dyspnea and chest pain. She was diagnosed as Gorham disease who was definitively treated with $V$. album extract for chylothorax that was refractory to standard conservative management.

Key Words: chylothorax; osteolysis, essential; pleurodesis

Gorham disease is a very rare disease which is specialized with destructive and unregulated proliferation of lymphatic or vascular capillaries within soft tissue and especially bone [1]. These patients usually have lots of clinical characteristics, such as bone pain, pathologic fracture, and bony deformity in extremities that are occurred in young adult or childhood [2]. If Gorham disease is complicated with chylothorax, it is very lethal. Pleurodesis using sclerosing agents, such as talc and variable antibiotics, is known to be a reasonable treatment option for chylothorax. We report the first clinical trial of treatment for chylothorax in Gorham disease using Viscum album extract.

\section{CASE REPORT}

A 14-year-old female (42 $\mathrm{kg}$ of body weight and $156 \mathrm{~cm}$ of height) presented with intractable dyspnea and right pleuritic chest pain that lasted 2 days. A chest X-ray revealed a massive pleural effusion in the right thoracic cavity (Figure 1A). We performed a closed thoracostomy with $28 \mathrm{~F}$ chest tube emergently. The amount of initial drainage was $2,500 \mathrm{ml}$, and then the symptoms of cardiac tamponade disappeared. Laboratory tests revealed that the pleural effusion was a chy-

\footnotetext{
Received on March 8, 2016 Revised on September 2, 2016 Accepted on September 6, 2016 Correspondence to: Su Wan Kim, Department of Thoracic and Cardiovascular Surgery, Jeju National University Hospital, Jeju National University School of Medicine, 15 Aran 13-gil, Jeju 63241, Korea

Tel: +82-64-754-8125, Fax: +82-64-757-8276, E-mail: 95swan@gmail.com

*No potential conflict of interest relevant to this article was reported.
}

(c) This is an Open Access article distributed under the terms of the Creative Commons Attribution Non-Commercial License (http://creativecommons.org/ licenses/by-nc/4.0/) which permits unrestricted non-commercial use, distribution, and reproduction in any medium, provided the original work is properly cited. Copyright (c) 2018 The Korean Society of Critical Care Medicine 
lothorax with a turbid-pinky color containing $121 \mathrm{mg} / \mathrm{dl}$ of triglyceride, $83 \mathrm{mg} / \mathrm{dl}$ of total cholesterol, and $99 \%$ of lymphocytes.

The patient had been diagnosed as having Gorham disease when she was 5 years old. At that time, she had been suffering from high fever and dyspnea and had been diagnosed with left-side empyema. She had undergone decortication through a thoracotomy instead of videoassisted thoracoscopic surgery because of her severe pleural adhesions. After the operation, laboratory tests revealed a chylothorax in the left pleural space. She could be discharged four months after the operation because of long-term total parenteral nutrition for prolonged drainage of chyle. A computed tomography and bone scan demonstrated multifocal osteolytic lesions and fractures in the clavicle, scapula, humerus, ankle, hip, and sternum (Figure 1B and C). Furthermore, the left thoracic cage had a deformity caused by a previous thoracic surgery.
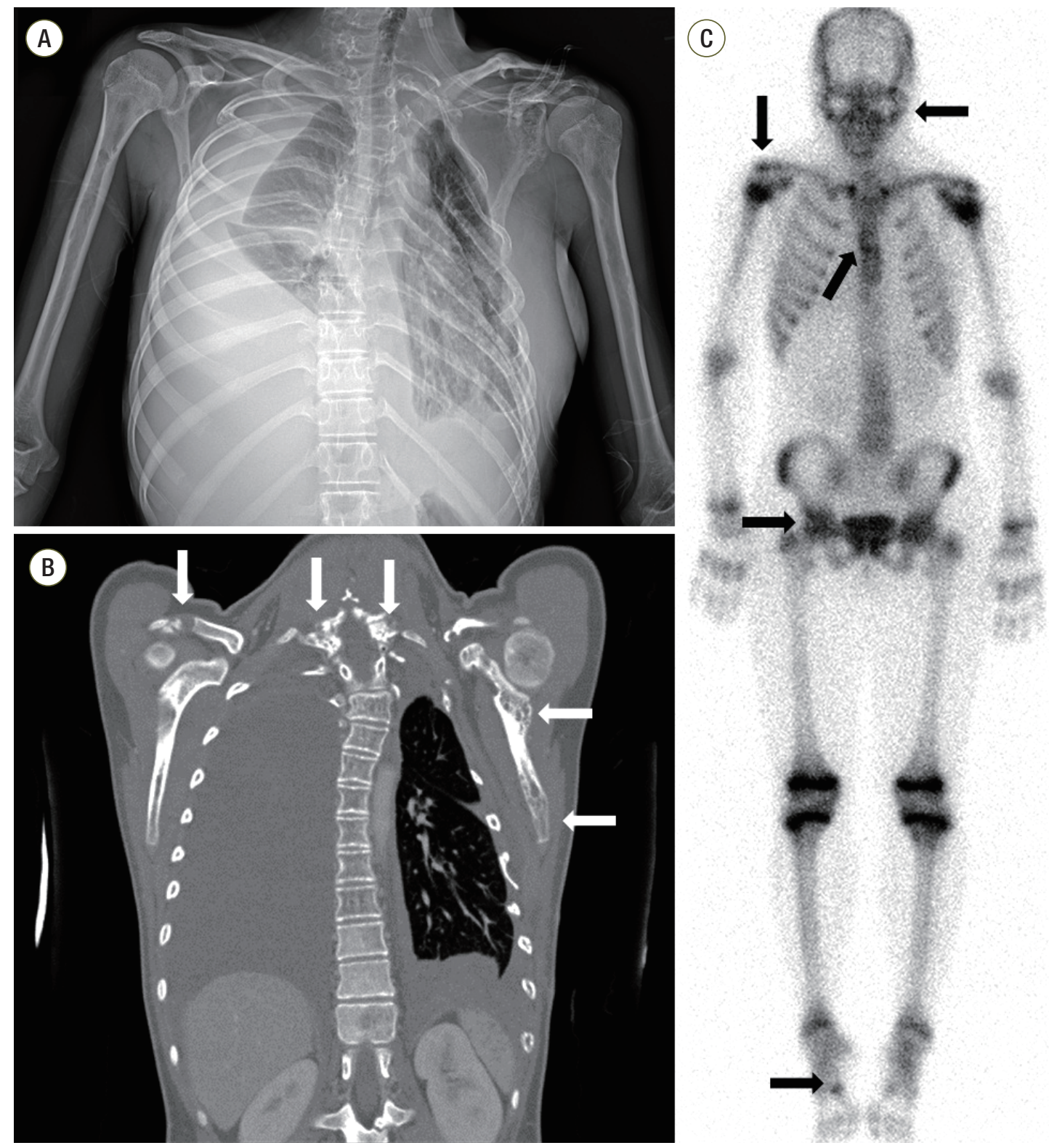

Figure 1. A chest X-ray revealing a massive pleural effusion in the right thoracic cavity (A). White and black arrows indicate multifocal osteolytic lesions and fractures in the clavicle, scapula, ankle, hip, and sternum in computed tomography (B) and bone scans (C). 
Five months prior, the patient had been admitted to our pediatric department because of chylothorax in the right pleural cavity and managed with repeated pleural tapping and supportive care including total parenteral nutrition and interferon therapy. Interferon alpha-2b 250 million IU was injected through subcutaneous tissue six times over 14 days and 500 million IU three times over 7 days. However, the pleural drainage persisted, and the patient suffered from fever, chills, and nausea. Two months after admission, the amount of pleural effusion was acceptably decreased on chest X-ray, but she could not tolerate the supportive care. The patient and her parents strongly wanted a discharge, and the patient was followed up regularly in the outpatient department.

In this time, we decided to perform a chemical pleurodesis using an extract of $V$. album (European mistletoe) (ABNOBA viscum F; ABNOBA Heilmittel Pforzheim, Germany) four days after the admission. Two ampoules of ABNOBA viscum F (100 mg) mixed with $200 \mathrm{ml}$ normal saline were infused into the thoracic tube after the right lung was fully re-expanded. The repeated pleurodeses were performed at 3 and 8 days after the first pleurodesis through the similar manner. The amount of pleural drainage decreased constantly from over 1,000 $\mathrm{ml}$ per day to $40 \mathrm{ml}$ per day. Five days after the last pleurodesis, we removed a chest tube because of the decreasing amount of pleural drainage despite the oral intake for 3 days. The patient was discharged 3 days after chest tube removal (Figure 2A) and followed up for 9 months with a normal diet (Figure 2B). Table 1 demonstrates the clinical courses including pleural drainage and events.

\section{DISCUSSION}

In Gorham disease, chylothorax results from thoracic duct invasion or connecting of the lymphatic dysplasia into the pleural space. Treatment methods in Gorham disease with chylothorax include closed thoracostomy, excision of the pleura, pleural symphysis, surgical ligation of the thoracic duct, radiation therapy, instillation of corticosteroids, alpha- $2 \mathrm{~b}$ interferon, and biphosphanates (clodronate, pamidronate) [3-5]. In some cases, interferon alpha with its anti-angiogenic properties has been successful in treating life-threatening hemangiomas in infancy and in Gorham disease [5]. However, in our case, the interferon therapy was not consistently effective,
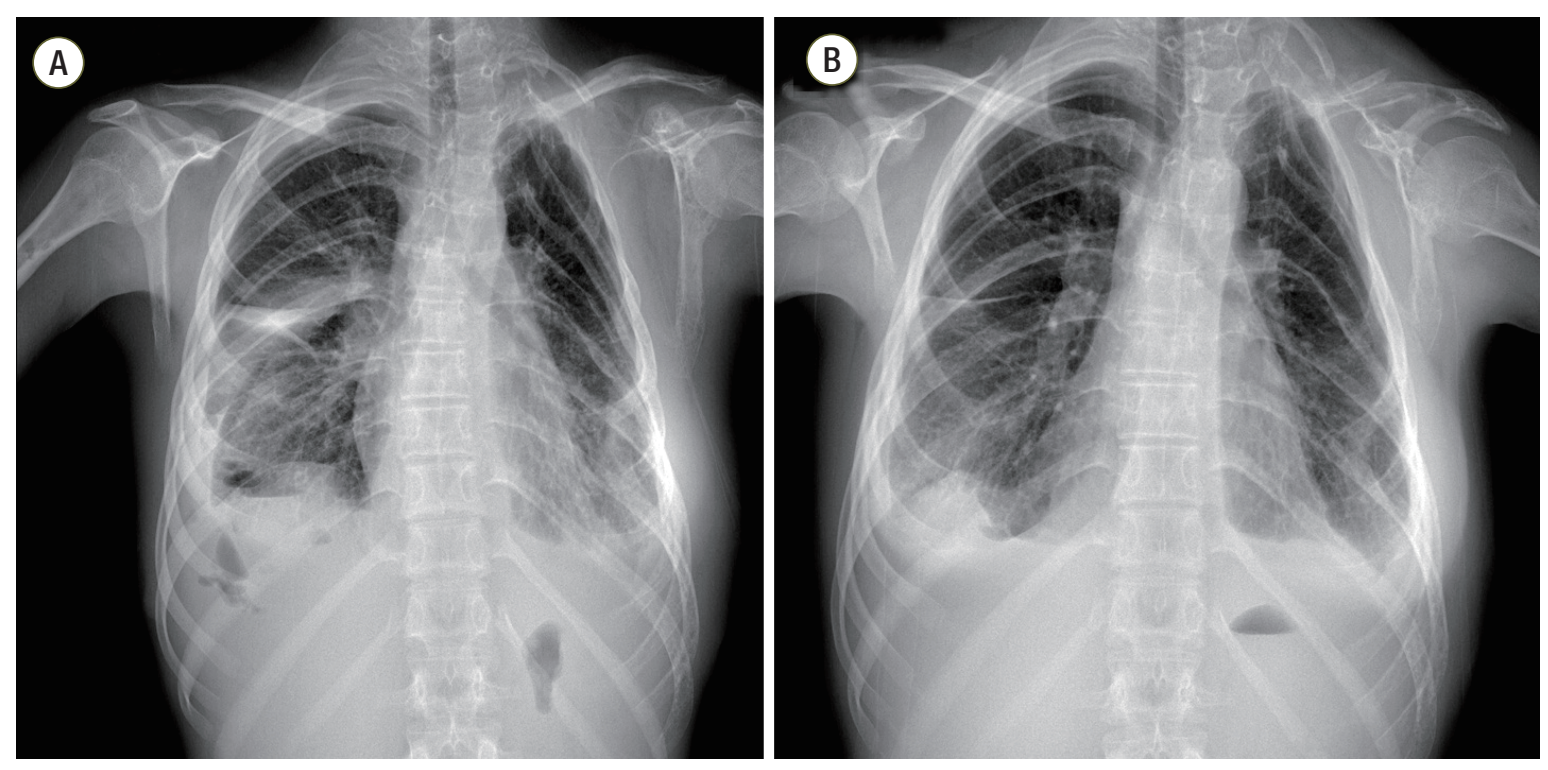

Figure 2. (A) A chest X-ray showing localized effusions in the right pleural cavity just before discharge. (B) There was no aggravating chylothorax in a follow-up chest X-ray 9 months after discharge. 
Table 1. In-hospital course and amount of pleural drainage

\begin{tabular}{|crc}
\hline Hospital day & Amount of drainage $(\mathrm{ml})$ & Event \\
\hline 1 & 2,500 & Initial drainage \\
\hline 2 & 900 & \\
\hline 3 & 970 & \\
\hline 4 & 2,580 & \\
\hline 5 & 820 & \\
\hline 6 & 1,020 & \\
\hline 7 & 180 & \\
\hline 8 & 1830 & \\
\hline 9 & 450 & \\
\hline 10 & 380 & Pleurodesis \\
\hline 11 & 330 & \\
\hline 12 & 310 & \\
\hline 13 & 370 & Pleurodesis \\
\hline 14 & 170 & Oral intake \\
\hline 15 & 160 & Chest tube removal \\
\hline 16 & 60 & \\
\hline 17 & 40 & \\
\hline 18 & 40 & \\
\hline
\end{tabular}

and it caused various side effects, such as fever, chills, nausea, and vomiting. Furthermore, we assumed that an open thoracic surgery such as decortication, pleurectomy, or thoracic duct ligation might result in chest wall deformities, leading to respiratory disability in the near future, and we could not guarantee any surgical effects. For these reasons, we decided to perform a chemical pleurodesis.

Injection of a sclerosing agent into the pleural cavity can promote an inflammatory reaction in the pleura, resulting in the obliteration of the pleural cavity and resolution of an air leak or pleural effusion. A few of sclerosing agents such as tetracyclin, hydrophilic silica, erythromycin, autologous blood, and talc slurry have been used to induce pleural fusion, and a numerous studies have researched their efficacy and complications. Common complications of these agents include chest pain, tachycardia, high fever, and dyspnea. Although talc is the most effective and favored sclerosing agent, it has serious complications including acute respiratory distress syndrome, acute pneumonitis, and pulmonary edema [6]. Therefore, a number of investigations are being conducted to search for new agents for pleurodesis.

ABNOBA viscum $\mathrm{F}$ is a $V$. album extract known as an European mistletoe that grows on the genus Fraxinus trees. $V$. album extract is a commonly used complementary anti-cancer drug in European countries. It can enhance life quality by decreasing the side effects of radiotherapy and chemotherapy, and also stimulates the immune system and improves survival [7]. A lot of literatures have reported favorable results by using the extract for chemical pleurodesis in the patient with malignant pleural effusion. We also found it successful for managing congenital chylothorax [8].

We initially performed standard conservative managements with chyle drainage through repeated thoracenteses and total parenteral nutrition and attempted to apply interferon alpha-2b. Unfortunately, the pleural drainage persisted for 2 months, and the patient was intolerable to the side effects. Because this was the first trial of intrapleural instillation of $V$. album extract in an adolescent who was refractory to management for chylothorax, the optimal dosage of $V$. album extract had not been established. The amount of the drug was determined bases on the dosage for prolonged pneumothorax and malignant pleural effusion in adult patients [6]. Although the usual starting dose of ABNOBA viscum $F$ is $100 \mathrm{mg}$, which can be increased to 500 $\mathrm{mg}$ in adults, we used two ampules (200 mg of ABNOBA viscum F) per pleurodesis because of the patient's lower body weight and her youth out of concern about potential side effects.

In conclusion, although Gorham disease is a very rare disorder, a concomitant chylothorax is a lethal complication and hardly treatable. The V. album extract is introduced as a modern sclerosing agent for chemical pleurodesis. We suggest that chemical pleurodesis using an extract of V. album for intractable chylothorax in patients with Gorham disease is a reasonable treatment option, and a standardization of its use should be established through various experiences and long-term follow-up. 


\section{ORCID}

Su Wan Kim

https://orcid.org/0000-0002-6531-7266

\section{REFERENCES}

1. Choma ND, Biscotti CV, Bauer TW, Mehta AC, Licata AA. Gorham's syndrome: a case report and review of the literature. Am J Med 1987;83:1151-6.

2. Kim BJ, Kim TH, Kim DJ, Noh D, Ham SJ, Lee S. A successfully treated case of gorham-stout syndrome with sternal involvement. Korean J Thoracic Cardiovasc Surg 2015;48:90-4.

3. Duffy BM, Manon R, Patel RR, Welsh JS. A case of Gorham's disease with chylothorax treated curatively with radiation therapy. Clin Med Res 2005;3:83-6.

4. Hammer F, Kenn W, Wesselmann U, Hofbauer LC,
Delling G, Allolio B, et al. Gorham-stout disease-stabilization during bisphosphonate treatment. J Bone Miner Res 2005;20:350-3.

5. Kuriyama DK, McElligott SC, Glaser DW, Thompson KS. Treatment of Gorham-stout disease with zoledronic acid and interferon- $\alpha$ : a case report and literature review. J Pediatr Hematol Oncol 2010;32:579-84.

6. Cho SJ, Kim SW, Chang JW. Acute pneumonitis consequent on pleurodesis with Viscum album extract: severe chest images but benign clinical course. Multidiscip Respir Med 2014;9:61.

7. Horneber MA, Bueschel G, Huber R, Linde K, Rostock M. Mistletoe therapy in oncology. Cochrane Database Syst Rev 2008;(2):CD003297.

8. Cho HJ, Na KJ, Kim DW, Choi YE, Ma JS, Jeong IS. Chemical pleurodesis using a Viscum album extract in infants with congenital chylothorax. Eur J Pediatr 2014;173:823-6. 